\title{
O USO DE DOCUMENTÁRIOS PARA O DEBATE CIÊNCIA-TECNOLOGIA-SOCIEDADE (CTS) EM SALA DE AULA
}

\begin{abstract}
RESUMO: A partir das experiências vivenciadas em uma disciplina sobre estudos Ciência, Tecnologia e Sociedade (CTS) verificou-se o forte potencial de alguns documentários para a promoção do debate desta articulação. A proposta deste artigo é apresentar alguns documentários e suas características de cunho CTS. Desse modo o artigo apresenta um enfoque informativo e torna-se possível subsídio para auxílio a professores que pretendem discutir CTS em suas aulas. Os documentários aqui descritos caracterizam-se como recursos para a elevação do pensamento crítico e postura cidadã das pessoas e para a promoção de discussões/reflexões, entre educadores e formadores, sobre a realidade vigente e a tríade CTS, culminando em possíveis mudanças escolares. Palavras-chave: Recursos didáticos, mídias no ensino, filmes documentários.
\end{abstract}

Leila Cristina Aoyama Barbosa*

Walter Antonio Bazzo**

\section{THE USE OF DOCUMENTARIES FOR SCIENCE-TECHNOLOGY-SOCIETY (STS) DISCUSSION IN THE CLASSROOM}

ABSTRACT: Based on the experiences in a discipline which studies on Science, Technology and Society (STS) there was strong potential for some documentaries to promote discussion of these issues. The purpose of this paper is to present some documentary films and their features related to STS. In this way, this paper presents an informative approach and it becomes possible to aid teachers who want to discuss STS in their classes. The films described here are characterized as resources to promote critical thinking and civic attitude of the people and to encourage discussions / reflections among educators and trainers on the current reality and the triad STS, resulting in possible changes in school.

Keywords: Teaching resources, media in education, documentary films.
*Doutoranda no Programa de
Pós-Graduação em Educação
Científica e Tecnológica da
Universidade Federal de Santa
Catarina (UFSC). Professora
titular da Escola Técnica
Estadual de Rondonópolis/MT
Email: leila.aoyama@gmail.com
* * Professor do Departamento
de Engenharia Mecânica e do
Programa de Pós-Graduação
em Educação Científica e
Tecnológica da Universidade
Federal de Santa Catarina
(UFSC).
Email: wbazzo@emc.ufsc.br 


\section{INTRODUĈ̣̃O}

A cinematografia apresenta certo fascínio pela ficção científica quando esta retrata previsões para o futuro da humanidade e do planeta. $\mathrm{Na}$ década de 1960, se materializava no filme 2001: uma odisseia no espaço, um século XXI com a interação entre humanos e computadores. No mesmo ano que intitula a obra clássica de George Orwell (Mil novecentos e oitenta e quatro), Michael Radford lançava seu filme baseado no livro, que se configurou como cópia fiel deste ao relatar o funcionamento de um mundo no qual o governo domina as massas controlando os seus pensamentos.

Ainda na década de 1980, surgia a trilogia De volta para o futuro, que nos mostrava um novo tempo cheio de máquinas e hologramas e nos fazia pensar sobre o futuro e o passado por meio de universos paralelos: um encantamento aos adolescentes e jovens da época. Já ao fim da década de 1990, foi rodado o filme baseado no clássico de Aldous Huxley, Admirável mundo novo, talvez, aquele que mais se aproxima com o modo de vida e realidade deste início de século XXI. E a virada do milênio ainda nos proporcionou diversos filmes com focos variados, porém sempre buscando a relação entre humanos e a tecnologia, como A. I. - Inteligência Artificial; Eu, robô e até mesmo Avatar. Tais filmes, implicitamente, apresentam essência filosófica aos nos fazer pensar sobre posturas humanas com seus próximos, com os demais seres vivos e com o próprio planeta, além de trazer reflexões sobre a ciência contemporânea que o ser humano imaginava existir em algumas décadas à sua frente. Cabe lembrar que alguns desses filmes, como Admirável mundo novo, consegue caracterizar bem os tempos de hoje.

Por diversas vezes, talvez tenhamos assistido a filmes e à televisão sem o intuito de pensar criticamente neles, visto que, geralmente, o objetivo dessas mídias é o entretenimento e proporcionar momentos de distração e lazer. No entanto, durante a disciplina "Ciência, Tecnologia e Sociedade - questões contemporâneas" do Programa de Pós-Graduação em Educação Científica e Tecnológica (PPGECT), da Universidade Federal de Santa Catarina (UFSC), foi possível verificar que a utilização de mídias pode adquirir uma nova função para o debate de temas da tríade Ciência-Tecnologia-Sociedade (CTS).

Essa disciplina, desenvolvida no semestre 2012/1, apesar de se tratar de uma matéria optativa de um curso de pós-graduação, configura-se como uma formação continuada de professores que se dedica aos estudos CTS, pois além de receber os alunos regularmente matriculados no PPGECT/UFSC, completa suas vagas com alunos especiais (de outros cursos ou sem vínculo com a universidade). Desse modo, torna-se uma oportunidade para compartilhar experiências educacionais e para a qualificação profissional, visto que abre espaço para que os professores possam refletir sobre sua prática docente, sobre as situações vivenciadas em sala de aula e para que eles busquem metodologias alternativas de ensino.

No decorrer das aulas dessa disciplina, foram utilizados vídeos documentários como estratégia promotora de discussão/reflexão de temas com enfoque 
em CTS. Dentre eles, foram abordados os seguintes aspectos: o poder das corporações na sociedade atual; o uso que fazemos da tecnologia e da internet no século XXI; a relação que existe entre ser humano e meio ambiente, entre outros.

Temas como esses se configuram como importantes para formadores de opinião, para educadores que buscam atualizar conhecimentos no campo CTS e para aqueles que vislumbram a ascensão de um pensamento crítico coletivo que exige a desalienação humana quanto às questões político-sociais (FREIRE, 2005).

O objetivo deste artigo é demonstrar o potencial de filmes documentários como subsídio para a discussão CTS nas diversas modalidades educacionais. Para tanto, será apresentada a descrição de alguns dos documentários que foram utilizados nas aulas da disciplina "Ciência, Tecnologia e Sociedade - questões contemporâneas". Nesses documentários, foi detectado forte cunho para a promoção de discussões CTS, de maneira que eles podem ser utilizados em cursos de formação inicial e/ou continuada de professores ou em aulas da educação básica que objetivem promover reflexões desse caráter.

\section{ASPECTOS HISTÓRICOS DA RELAC̣ÃO ENTRE DOCUMENTÁRIOS E EDUCAC̣ÃO}

Contemporaneamente, diversos autores (MORAN, 1995; BENTES, 2008a; GOMES, 2009) destacam o potencial da utilização de vídeos como recurso didático educacional. Entretanto, analisando a historiografia do surgimento de filmes do tipo documentário, é possível verificar que a relação entre estes e a educação se apresenta desde os tempos em que essa produção se iniciou (JESUS, 2008). Além disso, nota-se que esses filmes começaram a ser produzidos justamente para atender fins educativos.

A primeira vez que o termo "documentário" foi utilizado aconteceu no ano de 1926, quando John Grierson, produtor e estudioso de cinema, assim denominou o filme produzido por Robert Flaherty, Nannok do Norte (1922), que mostrava o cotidiano de uma família esquimó. Para Grierson, o filme de Flaherty trazia uma linguagem diferente daquela utilizada nos filmes sobre viagens e comunidades.

Desse modo, o produtor escocês fundou a escola inglesa de documentário com características marcantes para esse gênero cinematográfico, que trazia uma vOz over informativa e clara sempre sobreposta às imagens, passando-nos toda a informação, sem nunca sabermos da identidade do narrador. Esse modelo ficou conhecido como documentário clássico (RAMOS, 2008) e Grierson acreditava que esse tipo de filme se tornaria uma metodologia "para melhor educar a massa desinformada" (JESUS, 2008, p. 236). Por isso, o documentário ficou associado como uma forma de cinema voltada para a educação com finalidades informativas ou transmissoras de conteúdos.

A partir de 1960, o desenvolvimento de equipamentos de filmagem mais sofisticados transformou o modo de fazer cinema. Nascia um segundo modelo de documentário: o observacional. 
A evolução tecnológica trouxe novos métodos de filmagem, baseados na improvisação e na espontaneidade. Numa concepção tecnicista, o modo observacional de representação preocupou-se em comunicar um sentido de acesso imediato ao mundo, situando o espectador na posição de observador ideal. Para tanto, suprime o roteiro, minimiza a direção, privilegia o plano-seqüência sincrônico e a montagem que enfatiza a duração da observação, renuncia ao comentário, à música off, aos letreiros, às encenações e às entrevistas. (IBID, 2008, p. 239)

Indiferente da classificação que o documentário receba (clássico ou observacional) é possível perceber o caráter crítico presente em sua essência, visto que sua função é "expor com clareza determinadas informações necessárias à conscientização do indivíduo" (RAMOS, 2008, p. 17). Jesus (2008) apresenta ideias convergentes ao afirmar que esse tipo de filme é muito mais do que uma opção alternativa à produção ficcional. $\mathrm{O}$ documentário "foi pensado para formar a opinião pública” (IBID, p. 236).

De acordo com Penafria (1999, p. 20), “o filme documentário é aquele que, pelo registro do que é e acontece, constitui uma fonte de informação para o historiador e para todos os que pretendem saber como foi e como aconteceu". Torna-se, então, um objeto histórico, um autêntico documento com forte potencial de utilização em escolas.

Mais do que um mero suporte para a educação, o filme pode ser tratado como fonte de formação humana. (...) No entanto, com base em fundamentos teóricos que permitam compreender essa dinâmica, a educação escolar pode contribuir para a decodificação dos interesses sociais presentes na construção das imagens fílmicas, abrindo horizontes para a sua ressignificação (LOUREIRO, 2003, p. 95).

A indústria cinematográfica tem evoluído cada vez mais e os filmes documentários continuam sendo produzidos com o objetivo de informar, porém, não no aspecto técnico ou teórico. Os documentários pretendem informar sobre situações e realidades vigentes de maneira a influenciar a consciência crítica das pessoas.

Com a facilidade do compartilhamento de informações e arquivos pela internet, tornou-se mais fácil a obtenção desse tipo de filme. Nas próximas seções, serão apresentadas as sinopses e comentários de alguns documentários que podem ser utilizados em espaços educacionais. Para tanto, como o objeto de estudo deste trabalho é demonstrar a relação entre documentários e a perspectiva CTS, a próxima seção contempla algumas informações sobre esse enfoque educacional.

\section{PERSPECTIVA CTS NA EDUCAÇÃO}

A educação brasileira muito se transformou nas últimas décadas no que condiz à substituição de um modelo pautado na transmissão de conteúdos por uma vertente mais progressista de educação. 
Baseada na mediação de conhecimentos, esse segundo modelo preocupa-se também com a formação crítica do ser humano. O enfoque CTS, que vai ao encontro desse pensamento, apresenta-se como uma alternativa na conquista desse objetivo, pois atua na modificação dos valores capitalistas e individualistas vigentes e auxilia na produção da autonomia do pensamento crítico em indivíduos, ao conciliar temas científicos com a vida em sociedade (PINHEIRO, SILVEIRA \& BAZZO, 2007).

Desde as décadas de 1960/1970, estudiosos, ativistas e pesquisadores discutem sobre o modelo desenvolvimentista que a sociedade adotou em prol da tecnologia e da ciência. Pela análise do modo como ciência e tecnologia envolvem a sociedade contemporânea, tornou-se objetivo desse grupo a desmistificação do modelo linear de progresso (AULER, 2007), que acredita que a partir do desenvolvimento científico se chega ao desenvolvimento tecnológico, econômico e social como se esse processo acontecesse em uma evolução cronológica. Sendo assim, a perspectiva CTS busca a discussão/reflexão das limitações e da serventia da ciência e da tecnologia, não para desqualificar o conhecimento, mas para desmistificar concepções errôneas (CEREZO, 2004) como as já identificadas em algumas investigações.

Gil Pérez et al. (2001) evidencia sete visões deformadas dos professores sobre o trabalho científico: a) concepção empírico-indutivista e ateórica; b) visão rígida de ciência infalível; c) visão aproblemática e a-histórica; d) visão exclusivamente analítica; e) visão acumulativa de crescimento linear dos conhecimentos científicos; f) visão individualista e elitista da ciência e, g) visão socialmente neutra da ciência. Também Auler e Delizoicov (2006) comentam sobre três construções históricas geradas pela concepção de progresso linear da ciência e da tecnologia: a) superioridade/neutralidade do modelo de decisões tecnocráticas; b) perspectiva salvacionista/redentora atribuída à ciência-tecnologia e, c) o determinismo tecnológico. Todas essas concepções, quando manifestadas em sala de aula pelos professores, podem se estender aos alunos de modo que a ciência e a tecnologia continuem com o status de solucionadora dos problemas da humanidade, porém, pertencentes a um grupo restrito e pequeno de pessoas (os cientistas).

As discussões do movimento CTS avançaram de maneira a buscar modos de conscientizar as pessoas sobre as relações vigentes entre avanços tecnológicos e a sociedade. Observando essa finalidade, percebe-se que a escola se torna um lugar propício para realizar discussões sobre essas temáticas e que a perspectiva CTS pode se tornar o elo entre a cultura científica e humanística (BAZZO, 2012).

Os enfoques em CTS também pretendem que a alfabetização contribua para motivar os estudantes na busca de informação relevante e importante sobre as ciências e as tecnologias da vida moderna, com a perspectiva de que possam analisá-la e avaliá-la, refletir sobre essa informação, definir os valores implicados nela e tomar decisões a respeito, reconhecendo que a própria decisão final está inerentemente baseada em valores (CUTCLIFFE, 1990 apud BAZZO et al., 2003, p. 144). 
Santos (2008) aponta para o mesmo caminho ao ratificar que o uso da perspectiva CTS não visa assumir comportamentos tecnofóbicos ou tecnófilos; porém é essencial para que os estudantes reflitam "sobre a sua condição no mundo frente aos desafios postos pela ciência e tecnologia” (Ibid, p. 122).

Em relação aos currículos orientados pela perspectiva CTS, estes devem procurar

evidenciar como os contextos social, cultural e ambiental, nos quais se situam a ciência e a tecnologia, influenciam a condução e o conteúdo das mesmas; como ciência e tecnologia, por sua vez, influenciam aqueles contextos e, finalmente, como ciência e tecnologia têm efeitos recíprocos e suas inter-relações variam de época para época e de lugar para lugar (SANTOS \& MORTIMER, 2002, p. 11).

A adoção de currículos com essa abordagem é propícia para o momento atual em que se vive, pois nota-se o domínio de certo cientificismo, a influência dos especialistas científicos e também o deslumbre humano pelas máquinas; tais fatos levantam o questionamento: a ciência e tecnologia servem à humanidade ou os seres humanos servem às máquinas e tornaram-se reféns delas?

Esse tipo de questionamento surge quando assistimos a vídeos documentários como os que serão descritos na seção abaixo. Quando assistidas e discutidas em grupo, estas mídias se tornam excelente opção de recurso didático para ser utilizado tanto em formação de professores quanto no ensino escolar devido ao seu conteúdo ilustrativo, contextualizado e reflexivo.

\section{EXEMPLOS DE DOCUMENTÁRIOS COM POTENCIAL PARA DISCUSSÕES CTS}

Conforme descrito em seções anteriores, filmes do tipo documentário têm por função registrar um fato ocorrido de modo a servir como fonte de informação para outras pessoas. Sobre o uso de vídeos na escola, Moran (1995) indica a utilização deles como sensibilização a fim de motivar a discussão de temas, despertar a curiosidade e o desejo de pesquisa nos alunos em aprofundar sobre o assunto tratado no vídeo.

No entanto, convém lembrar que do mesmo modo que a ciência e a tecnologia não são neutras (BAZZO et al., 2003), o mesmo pensamento serve para os documentários, pois se trata da visão de uma ou várias pessoas (roteirista, diretor, cinegrafista, entre outros) sobre um determinado tema ou contexto.

A maneira como o documentarista entende esses vínculos e se coloca frente ao mundo que filma revela como o seu posicionamento político-ideológico entra em jogo para apresentar as histórias e os argumentos que ele deseja contar, e as imagens e indivíduos que deseja mostrar. Estas histórias e imagens, organizadas de uma certa forma, promovem um conjunto de valores e ideias em detrimento de outros (Rezende, 2008, p. 25). 
Sendo assim, o documentário tem uma ideia a ser transmitida e é importante que o espectador compreenda que nenhuma mensagem é neutra; ela sempre estará atuando a favor ou contrariamente ao sistema implantado.

Bentes (2008a) destaca que é necessário “enxergar” a pesquisa por trás das questões abordadas, perguntar pelos métodos utilizados, pelos temas e personagens consultados e entender os motivos para a produção de tal vídeo. É preciso utilizar nosso pensamento crítico para avaliar o conteúdo do documentário.

A análise de documentários nos exige conferir uma grande atenção às questões éticas, estéticas, políticas e aos impasses que delas surgem, já que o documentário é um campo de prática e criação audiovisual em que as relações entre essas dimensões se apresentam de forma bastante complexa (Rezende, 2008, p. 25).

Desse modo, a discussão em grupo (de estudantes ou professores) é importante como espaço para conhecimento de diferentes pontos de vista e para a realização da análise dos filmes documentários.

A seguir, são apresentadas as sinopses de três vídeos assistidos nas aulas da disciplina "Ciência, Tecnologia e Sociedade - questões contemporâneas" demonstrando seu potencial de discussão/reflexão de temas CTS. Os dois primeiros, devido a sua maior profundidade filosófica, se destinam à formação de professores ou aos cursos de graduação. Porém, se forem feitas adaptações dos questionamentos de reflexão, ou com a mediação do professor, podem também ser utilizados em aulas do Ensino Médio. O terceiro filme aqui descrito pode ser utilizado nos diversos níveis educacionais, a partir do Ensino Fundamental. Todos os documentários podem ser encontrados no site YouTube.

\section{Documentário 01: Nós que aqui estamos por vós esperamos}

Produzido em 1998 e lançado no ano seguinte, o filme brasileiro produzido por Marcelo Masagão é o mais filosófico dos três documentários descritos neste trabalho. Com duração de 55 minutos, "Nós que aqui estamos por vós esperamos" retrata memórias do século XX a partir de personagens mundialmente conhecidos e tantos outros anônimos.

A profundidade do filme para a reflexão se dá pela inexistência de narração ou falas. Trata-se de uma composição de imagens de arquivos, fragmentos de outros documentários e algumas obras clássicas do cinema unidas a belas canções instrumentais.

O documentário relata sobre artes, comportamentos de gênero, mudanças sociais e econômicas, as diferenças entre os pensamentos da sociedade oriental e os da ocidental e o desenvolvimento da ciência e da tecnologia no século XX, que pode ser considerado como revolucionário para esses dois últimos elementos.

O vídeo é um convite à reflexão sobre as consequências oriundas das duas grandes guerras mundiais, as transformações vindas das máquinas e indústrias e a influência dos diversos líderes políticos. A ganância e a cobiça do ser humano por 
poder aparece em diversas situações, desde o sonho de uma pessoa em voar como um pássaro até a ideia de Hitler de alcançar uma raça ariana.

Por intermédio do documentário, o grupo participante da disciplina pôde discutir sobre as articulações CTS, analisar a falta de neutralidade da ciência e da tecnologia relembrando a história do projeto Manhattan ${ }^{1}$, perceber que o ponto frágil e manipulador da relação CTS encontra-se na sociedade e discutir questões educacionais sobre os obstáculos para o ensino de temas sociocientíficos na escola. O ponto culminante do debate foi perceber a mudança de valores e comportamentos neste início de século XXI. A sociedade é mais high tech, porém, mais consumista, individualista e egoísta. É o ter que se coloca à frente do ser (Fromm, 1982).

Para ser trabalhado com turmas do Ensino Médio, talvez se torne necessário que o professor elabore um roteiro com questões reflexivas, como, por exemplo: "Qual a importância do século XX para a humanidade? Como a ciência e a tecnologia se desenvolveram nesse tempo? O que mudou na sociedade em termos de igualdade e dignidade humana? Qual o posicionamento e a influência dos cientistas nas grandes guerras mundiais? Qual o papel e importância da tecnologia em nossas vidas atualmente?". Essas questões poderiam ser repassadas aos estudantes antes mesmo de eles assistirem ao documentário, na forma de um estudo dirigido, a fim de facilitar a posterior discussão em grupo. E, concordando com Bentes (2008b), que acredita que a produção audiovisual pode promover a renovação do modelo disciplinar dos currículos atuais, fica como sugestão a utilização desse documentário nas aulas de Artes, História, Geografia, Filosofia e Sociologia, em que sejam tratados temas ligados à sociedade e às transformações do século XX e seus fatos históricos.

\section{Documentário 02: The Corporation}

Lançado em 2003, o documentário, com duração de 145 minutos, dos canadenses Mark Achbar e Jennifer Abott, é baseado no livro de mesmo nome de Joel Bakan (The Corporation: the pathological pursuit of profit and power).

O vídeo apresenta um histórico de como grandes corporações mundiais alcançaram lugar de influência global que ultrapassam o campo da economia. É possível detectar o poder das corporações em questões sociais, políticas e ambientais e verificar que elas manipulam a mente das pessoas e se tornam responsáveis por muitas situações que encontramos no mundo contemporâneo, se tornando uma força maior que o Estado.

Esse filme apresenta elevado poder de criticidade ao misturar cenas de filmes, vídeos institucionais antigos, entrevistas e depoimentos de altos executivos, propagandas e anúncios de empresas e muitas outras imagens documentais. Por meio dele, mergulha-se em um mundo no qual o que vale é o lucro e o poder alcançado, e torna-se possível enxergar o universo inebriante de consumismo que as corporações têm criado. Trata-se de uma trama muito bem articulada que pode deixar de ser percebida pela sociedade que se aliena ao se preocupar, cada vez mais, somente com seu próprio conforto e com a aquisição de bens materiais. 
Barber (2008) afirma que ao pensar que conquistou o mundo das coisas, o consumidor, na verdade, está sendo consumido por essas coisas. Em seu livro Consumido, esse cientista político traz diversas ponderações a partir de suas pesquisas sobre mercado de consumo. Para ele, o mercado (que aqui podemos considerar também como as corporações) infantiliza adultos - ao mexer com seus desejos e fraquezas e torná-los consumidores insaciáveis; corrompe crianças - ao tratá-los como "mini" adultos na busca da fidelização dos pequenos por marcas e "engole" cidadãos ao lançar tantos produtos e marcas que dificultam o pensamento crítico das pessoas. Estamos fadados a comprar o mais novo, o mais tecnológico, não temos tempo para pensar; somente para agir, fazer. Perdemos a reflexão, ficamos com o reflexo (Ellul, em documentário produzido por Van Boekel, 1992).

Ao tratar sobre temas como a patologia do comércio por vendas, a exploração do trabalho humano, o enfraquecimento do poder do governo frente à mão invisível do mercado, a subestimação da força dos movimentos sociais, o poder do marketing e a relação das corporações com o meio ambiente e as comunidades locais, esse documentário é capaz de abalar as estruturas epistemológicas do indivíduo ao demonstrar uma realidade antes camuflada.

No grupo participante da disciplina, formado por professores da educação básica e acadêmicos, foi possível discutir sobre o poder das grandes corporações na sociedade, sobre como o consumismo atinge nossos estudantes e criam exclusões entre eles, como elas influenciam na escolha das carreiras profissionais e criam estereótipos ("bacana é o cara que tem o tênis 'da moda' e o celular 'top de linha"”). Enfim, como afirma o documentário, as corporações, ao transmitirem certos tipos de valores, modificam o modo de pensar e de se comportar do ser humano.

Para aqueles que desejarem se aprofundar mais nessa obra, é disponibilizado, na internet, um site em inglês (www.thecorporation.com) no qual é possível encontrar mais informações sobre o documentário e sobre o livro, bem como sugestões da utilização dessas obras na educação.

Por se tratar de um filme com mais de duas horas de duração, caso seja utilizado com estudantes do Ensino Fundamental ou Médio, o documentário deve ser fragmentado em partes que possam ser contextualizadas com os alunos. É necessário também que o professor tenha o cuidado de avaliar o perfil da turma e seu nível de entendimento para o vídeo para que não se torne uma atividade cansativa ou sem objetivo.

Como sugestão de questões de temáticas CTS que podem ser discutidas após o filme, tem-se: “Como surgiram as corporações? Quais as características do modelo econômico vigente (neoliberalismo)? A sociedade participa das decisões sobre ciência e tecnologia no Brasil? A mídia e a propaganda interferem em nosso modo de vida e escolhas de compras? O consumismo é algo a se preocupar atualmente? Qual a atuação dos cientistas na manutenção das grandes corporações?”

As questões aqui sugeridas podem ser tratadas em aulas de Geografia, Sociologia e História, mas também podem ser incorporadas em aulas de ciências 
quando se trabalha conteúdos atuais, como, por exemplo, os organismos geneticamente modificados. Nesse caso, não basta somente discutir o conceito dessa biotecnologia; é importante que os estudantes saibam qual a interferência desses produtos no meio ambiente e na saúde humana, bem como que eles entendam sobre a influência das corporações nessa situação.

\section{Documentário 03: A história das coisas}

Dentre os documentários apresentados neste trabalho, talvez "A história das coisas" seja o mais conhecido, pois é bastante utilizado em projetos de sensibilização de educação ambiental. Com linguagem simples, o filme The Story of Stuff (2007), de Annie Leonard, apresenta, em 21 minutos, um passo a passo da cadeia produtiva do consumo (da extração de matérias-primas para a produção de bens até o descarte destes) e uma análise dos padrões de consumo da sociedade americana, mas, que nos tempos atuais, se assemelham aos padrões de muitos países.

O vídeo revela as conexões existentes entre muitos processos industriais e os vários problemas ambientais e sociais que vivemos contemporaneamente. Trata-se de uma sensibilização e alerta pela urgência em buscarmos a sustentabilidade ambiental e a equidade social.

É recomendável a utilização dessa mídia em todos os níveis de ensino, devido a sua curta duração e ao seu fácil entendimento. Entretanto, ressaltamos que as discussões originadas pelo documentário podem adquirir complexidade de acordo com nível de senso crítico dos participantes envolvidos. Constitui-se, também, como fonte para desalienação e/ou chamar a atenção das pessoas para o consumismo exacerbado e o modo de vida neste século XXI.

Entre os participantes da disciplina "Ciência, Tecnologia e Sociedade questões contemporâneas", a discussão ficou em torno de questionamentos como: "Qual a necessidade de o ser humano adquirir bens novos? Como somos atingidos pelas obsolescências programada e perceptiva? A tecnologia ganhou autonomia (?), visto que os produtos já não são criados para satisfazer necessidades humanas, mas criam-se necessidades para justificar a produção de novos equipamentos? $\mathrm{O}$ Estado realmente perdeu o controle sobre as grandes corporações? Que "mão invisível" é essa que vem transformando os padrões de vida das sociedades? Por que não conseguimos "sair fora" do sistema mercantilista implantado? De que maneira a educação escolar pode auxiliar na mudança deste sistema?”

Como se observa, trata-se de questões complexas oriundas de um debate entre profissionais da educação que vai além da discussão de questões ambientais; tornam-se reflexões de problemas e situação sociais.

Outras informações sobre o documentário e o próprio vídeo e legendas, na versão brasileira, podem ser encontradas no site http:/ / www.sununga.com.br/ HDC/ e também em http://www.storyofstuff.org/, que divulga o projeto e disponibiliza outros documentários no mesmo formato, porém, sobre temas diversos, como The Story of Change (sobre mudanças no padrão de consumo), The Story of 
Broke (sobre a economia americana) e The Story of Electronics (sobre a quantidade de lixo eletrônico produzido no mundo).

Em caminho inverso aos demais documentários, a História das coisas virou livro em 2011 e se torna mais um instrumento para a discussão CTS, principalmente entre adolescentes, ao estimular a leitura e aquilo que denominamos "cultura da leitura" em nossos jovens (BAZZO, 2012), pois o pensamento e o senso crítico só tendem a se fortalecer a partir do contato e diálogo com obras literárias.

\title{
CONSIDERACְÕES FINAIS
}

O enfoque CTS na escola deixou de ser uma alternativa de ensino, pois o modelo de sociedade e de produção, neste início de século XXI, nos alerta para a urgência em discutirmos sobre esses temas e buscarmos soluções.

\begin{abstract}
Para isso necessitamos fomentar também uma revisão epistemológica da natureza da ciência e da tecnologia, abrir a caixa-preta da ciência ao conhecimento público, desmitificando sua tradicional imagem essencialista e filantrópica, e questionando também o chamado "mito da máquina" (nas palavras de Lewis Mumford), quer dizer, a interessada crença de que a tecnologia é inevitável e benfeitora em última instância. Pois, como coloca Dyson (1997, p. 48), fazendo eco de Haldane e Einstein, o progresso ético (e também epistemológico, devemos acrescentar) é, em última instância, a única solução para os problemas causados pelo progresso científico e tecnológico (BAZZO, et al., 2003, p. 143)
\end{abstract}

Filmes do tipo documentário mostram-se excelentes subsídios para o fomento de alteração de concepções deformadas de ciência e tecnologia, sendo capaz de demonstrar a sua não neutralidade e a relação que se estabelece entre a sociedade e esses outros dois elementos. Por isso, são considerados como potenciais recursos didáticos para o ensino quando se pensa em discutir temas sociopolíticos e se busca a democratização do debate científico.

Para tanto, é necessário que haja a adequação das reflexões de acordo com o nível e com o perfil dos participantes e, como defendem Moran (1995) e Gomes (2009), o acompanhamento da proposta pedagógica consciente às exigências de uma educação transformadora que priorize a formação do senso crítico e a formação para a cidadania.

\section{NOTA}

\footnotetext{
${ }^{1}$ Programa secreto americano, existente durante a Segunda Guerra Mundial, cujos esforços se concentravam na criação das primeiras armas nucleares.
} 


\section{REFERÊNCIAS BIBLIOGRÁFICAS}

AULER, D. Articulação entre pressupostos do educador Paulo Freire e do movimento CTS: novos caminhos para a educação em ciências. Contexto e educação, Ijuí, v. 22, n. 77, p. 167-188, jan./jun. 2007.

AULER, D., DELIZOICOV, D. Ciência-Tecnologia-Sociedade: relações estabelecidas por professores de ciências. Revista Electrónica de Enseñanza de las Ciencias, Vigo, Espanha, v. 5, n. 2, p. 337-355, 2006.

BARBER, B. R. Consumido: como o mercado corrompe crianças, infantiliza adultos e engole cidadãos. Rio de Janeiro: Record, 2008.

BAZZO, W. A. Cultura científica versus humanística: a CTS é o elo? Revista Iberoamericana de educación, Madri, n.58, p. 61-79, 2012.

.; PALACIOS, E.M.G.,; GALBARTE, J.C.G.; VON LINSINGEN, I.; CEREZO, J.A.L.; LUJÁN, J.L.; GODILLO, M.M.; OSORIO, C.; PEREIRA, L.T.V.; VALDÉS, C. Introdução aos estudos CTS (Ciência, Tecnologia e Sociedade). Madri: OEI, 2003

BENTES, I. Debate: cinema, documentário e educação - proposta pedagógica. In: Debate: cinema, documentário e educação. Programa Salto para o Futuro (MEC), Brasilia, ano 13, n. 11, p. 03-11, jun. 2008a.

. Cena contemporânea: novos sujeitos do discurso. In: Debate: cinema, documentário e educação. Programa Salto para o Futuro (MEC), Brasília, ano 13, n. 11, p. 41-44, jun. 2008b.

CEREZO, J. A. L. Ciência, Tecnologia e Sociedade: o estado da arte na Europa e nos Estados Unidos. In: SANTOS, L. W. (Org.). Ciência, Tecnologia e Sociedade: o desafio da interação. Londrina: IAPAR, p.11-46, 2004.

CUTCLIFFE, S. Ciencia, tecnología y sociedad: um campo interdisciplinar. In: MEDINA, M.; SANMARTÍN, J. (eds.). Ciencia, tecnología y sociedade: estúdios interdisciplinares en la universidad, en la educación y em la gestión pública. Barcelona: Anthrophos , 1990.

FREIRE, P. Pedagogia do oprimido. 47. ed. São Paulo: Paz e Terra, 2005.

FROMM, E. Ter ou ser? Rio de Janeiro: Zahar Editores, 1982.

GIL PÉREZ, D. et al. Para uma imagem não deformada do trabalho científico. Ciência \& Educação, Bauru, v.7, n.2, p.125-153, 2001

GOMES, L.F. Vídeos Didáticos: uma proposta de critérios para análise. Revista Travessias, Cascavel, v. 2, n. 3, 2008. Disponível em: <http://erevista.unioeste.br/index.php/travessias/article/ view/3128/ 2463>. Acesso em 12 jul. 2012.

JESUS, R.M.V. de. Escola e documentário: uma relação antiga. Revista HISTEDBR On-line, Campinas, n.32, p. 233-242, dez.2008. Disponível em: < http://www.histedbr. fae.unicamp.br/revista/ edicoes/32/art17_32.pdf>. Acesso em 12 jul. 2012.

LOUREIRO, R. Indústria cultural e educaşão em "tempos pós-modernos”. Campinas: Papirus, 2003.

MORAN, J.M. O vídeo na sala de aula. Comunicação e Educação, São Paulo, n. 2, p. 27-35, jan./abr. 1995. PENAFRIA, M. O filme documentário: história, identidade, tecnologia. Lisboa: Edição Cosmos, 1999.

PINHEIRO, N. A. M.; SILVEIRA, R. M. C. F; BAZZO, W. A. Ciência, tecnologia e sociedade: A relevância do enfoque CTS para o contexto do ensino médio. Ciência \& Educação, Bauru, v. 13, n.1, p. 71-84, abr. 2007.

RAMOS, G. Documentário e ficção, revendo uma história. IN: Debate: cinema, documentário e educação. Programa Salto para o Futuro (MEC), Brasília, ano 13, n. 11, p. 12-18, jun. 2008.

REZENDE, L. Como analisar um documentário? Questões estéticas e éticas. In: Debate: cinema, documentário e educação. Programa Salto para o Futuro (MEC), Brasilia, ano 13, n. 11, p. 25-29, jun. 2008.

SANTOS, W.L.P.S. Educação científica humanística em uma perspectiva freireana: resgatando a função do ensino de CTS. Alexandria Revista de Educação Ciência e Tecnologia, Florianópolis, v. 1, n. 1, p. 109-131, mar. 2008.

.; MORTIMER, E.F. Uma análise de pressupostos teóricos da abordagem C-T-S (Ciência Tecnologia - Sociedade) no contexto da educação brasileira. Ensaio: pesquisa em educação em ciências, Belo Horizonte, v.02, n. 02, p. 01-23, dez. 2002. Disponível em: <http://www.portal.fae.ufmg.br/ seer/index.php/ensaio/article/viewFile/21/52>. Acesso em: 10 jul. 2012. 
0 uso de documentários para o debate ciência-tecnologia-sociedade em sala de aula

VAN BOEKEL, J. The betrayal by techonology: a portrait of Jacques Ellul. Amsterdã: ReRun Produkties, 1992. documentário (54 min).

Data do Recebimento: $14 / 10 / 2012$

Data de Aprovação: 13/03/2013

Data da Versão Final: 14/03/2013 